\title{
Effect of Nanosilica on the Hydration Characteristics and Compressive Strength of Blended Basalt Cement Pastes
}

\section{Kh. A. Khalil}

Chemistry Department, Faculty of Science, Zagazig University, Zagazig, Egypt.

\begin{abstract}
7 HE EFFECTS of nanosilica (NS) on the hydration kinetics and mechanical strength development of blended basalt cement pastes of cementitious mixes were investigated. The measurements have been carried out on blended basalt cement pastes made with four dose levels of NS at different water to binder ratios. NS accelerates the hydration of blended basalt cement pastes. The addition of NS improves the mechanical strength and increases combined water contents, but free lime and bulk density decrease. Basalt acts as filled materials at early age and then its reactivity increases due to pozzolanic reaction. It has been concluded that partial substitution of blended basalt cement pastes up to 4 mass \% NS improves the mechanical and hydration characteristics in comparison with the control hardened pastes up to 90 days. The results can be mainly attributed to the ultrafine nature of NS. The phases formed have already been confirmed with XRD and DTA.
\end{abstract}

Keywords: Nanosilica, Basalt, Blended cement, Pozzolanic properties, Compressive strength.

The purpose of nano particle addition in cements is to stimulate the nucleation process during the early cement hydration. The earlier these nuclei are formed, the earlier they can grow to larger crystals of hydration phases and thereby accelerate the cement hydration. Due to the small size of nano particles, they provide very large surface areas. At the same time, these surfaces are so highly reactive that they may react with components from pore solution or may act as a nucleation site. The nano particle has also a large potential to react with components of the cement to form additional nuclei, like $\mathrm{SiO}_{2}$ particles in a pozzolanic reaction to form calcium silicate hydrates $(\mathrm{C}-\mathrm{S}-\mathrm{H})^{(1-6)}$.

Nano silica (NS) has showed a high pozzolanic reactivity in fresh and hardened states. In the fresh state, it has been found that, NS reduces setting times, increases the release of hydration heat, and modifies the rheological behavior of cement pastes and mortars ${ }^{(7-17)}$.

E-mail address; khalilali9@gmail.com ${ }^{*}$ Tel.:+201110808356,020552353628 
In the hardened state, researchers have reported that NS increases the compressive strength $(7-10,12,18,19)$, decreases the porosity and improves some aspects of durability $(10,11,14,17,20-24)$. Some works have found that, NS produces important mineralogical changes, mainly on $\mathrm{C}-\mathrm{S}-\mathrm{H}$ and portlandite $(\mathrm{CH})$. For C-S-H, NS accelerates its formation, the samples blended with NS have higher content of C-S- H, and it allows formation of longer C-S- $\mathrm{H}$ chains in comparison to the control samples ${ }^{(22-27)}$.

Researchers ${ }^{(21,28)}$ reported that the performance of concrete is generally improved by adding nanosilica. It was believed that the improvement of concrete by adding nanosilica is attributed to its filler effect and pozzolanic reaction. Recently, however, the small particle size of nano silica provides a large surface area, which speeds up the rate of cement hydration and pozzolanic reaction $^{(29)}$.

The effect of nanosilica on the rheological behavior of cementitious mixes, rheometric studies on cement mortars incorporating superplasticizer ${ }^{(30)}$, or not ${ }^{(13)}$, agree that the addition of nanosilica increases the water demand of cementitious mixes greatly, as compared with the control ones.

The addition of nanosilica to ordinary Portland cement (OPC) pastes was found to increase the compressive strength to an extent that was dependent on the nanosilica, water- to - bender ratio (w/b) and curing time ${ }^{(31-35)}$. Some researchers ${ }^{(31,33,34)}$ also reported a progressive increase in compressive strength with increasing NS content over the range from 0.2 to $10-12$ mass $\%$ of cement.

On the contrary, no improvement in compressive strength was observed by Leemann and Winnefeld [30] for OPC concrete mixes $(\mathrm{W} / \mathrm{B}=0.5)$ containing nanosilica and superplasticiers at dose level of $1.5 \%$ and $5 \%$ by mass of cement, respectively(curing times up to 28 days). However, recent studies by Givi et al. ${ }^{(36)}$ and Nazari and Rihai ${ }^{(10)}$ have shown mechanical strength improvements for concretes added with nanosilica.

Basalt is one of igneous rocks, which was formed during the cooling of magma in the old ages of the earth. The effect of limestone powder, basalt powder and marble powder as mineral admixtures on the fresh and hardened properties of self-compacting concrete was investigated ${ }^{(37)}$. Basalt as a mineral admixture was investigated, where the physical properties and chemical compositions were studied ${ }^{(38-40)}$. The effect of basaltic pumice on the mechanical and physical properties ${ }^{(41,42)}$ and sea water resistance of the concrete was studied ${ }^{(43)}$. The deterioration effect of blended cement combinations with red brick dust (RBD) and ground basaltic pumice (GBP) was investigated ${ }^{(44)}$. The effect of basalt powder on the rheological properties of fresh and hardened cement mortar ${ }^{(45)}$ was investigated. Binci et al. ${ }^{(46,47)}$ conducted the study to examine the possibility of using the industrial wastes of basaltic pumice as a

Egypt. J. Chem. 59, No.4 (2016) 
fine aggregate in concrete. They found that the basaltic pumice could be conveniently used for low abrasion and higher compressive strength concrete.

Using basalt fibers slightly increase the 28-days compressive strength of concrete containing fly ash and admixtures with a low water-cement ratio. In addition, the early compressive strength of concrete containing fly ash and admixtures may significantly increase due to the use of basalt fibers ${ }^{(48)}$.

The object of this study is to investigate the effect of nanosilica on the hydration characteristics and mechanical properties of hardened blended basalt cement pastes. This has been done via determining the chemically combined water contents, the free lime contents, thecompressive strength andthe bulk density at different ages of hydration. In addition, Phase composition has been examined using XRD and DTA.

Raw materials

\section{Experimental work}

Ordinary Portland cement $(O P C)$

Fresh ordinary Portland cement (blank sample) was supplied from Suze Portland Cement Company, Egypt. The chemical composition is given in Table 1. The Blaine surface area of OPC was $3488 \mathrm{~cm}^{2} \mathrm{~g}^{-1}$

Nanosilica (NS)

NS has been supplied from NanotechnologyLab, Faculty of Science, BeniSuief University, Egypt. The average particle size of nanosilica (NS) is $15 \mathrm{~nm}$ and the surface areais $95 \mathrm{~m}^{2} \mathrm{~g}^{-1}$. The amorphous nature of nanosilica particles andthemicrostructure were studied in earlier publications by means of X-ray diffraction(XRD), transmission electron microscopy ( TEM) and scanning electron microscopy( SEM) $(8,17,22,27)$. The chemical composition of NS is given in Table 1.

\section{Basalt Powder (BS)}

The fresh basalt has been provided from Abu Dareg Dasaltic Dyke, the North Eastern Desert (NED),Egypt. The fresh basalt was separately ground to pass $90 \mu \mathrm{m}$ sieve. The crystalline nature of basalt was verified in earlier publications using XRD,SEM, infra-red (IR) and differential scanning calorimetry (DSC) ${ }^{(38,40)}$. The chemical composition of basalt is given in Table 1 .

TABLE 1.Chemical composition of raw materials.

\begin{tabular}{|l|c|c|c|c|c|c|c|c|c|c|}
\hline \multirow{2}{*}{$\begin{array}{c}\text { Raw } \\
\text { materials }\end{array}$} & \multicolumn{10}{|c|}{ Chemical composition (mass \%) } \\
\cline { 2 - 12 } & $\mathrm{SiO}_{2}$ & $\mathrm{Al}_{2} \mathrm{O}_{3}$ & $\mathrm{Fe}_{2} \mathrm{O}_{3}$ & $\mathrm{CaO}$ & $\mathrm{MgO}$ & $\mathrm{SO}_{3}$ & $\mathrm{Na}_{2} \mathrm{O}$ & $\mathrm{K}_{2} \mathrm{O}$ & LOl & Total \\
\hline $\mathrm{OPC}$ & 20.24 & 4.95 & 4.02 & 61.58 & 2.63 & 2.49 & 0.49 & 0.21 & 2.25 & 98.8 \\
\hline $\mathrm{BS}$ & 59.37 & 15.39 & 11.4 & 9.68 & 1.87 & 0.06 & 0.24 & 0.40 & 1.50 & 99.91 \\
\hline $\mathrm{NS}$ & 98.61 & 0.01 & 0.01 & 0.01 & 0.01 & 0.29 & 0.3 & 0.045 & 0.71 & 99.99 \\
\hline
\end{tabular}

Egypt. J. Chem. 59, No.4 (2016) 


\section{Preparation of blended cement pastes}

Mixing

Mixed compositions of the prepared blended cement are shown in Table 2. Basalt is added as a partial replacement of cement and NS is added as a partial replacement of basalt. The dry constituents of $(\mathrm{OPC}+$ basalt $)$ and $(\mathrm{OPC}+$ basalt + nanosilica) were mechanically mixed for one hour in a porcelain ball mill using four balls to attain complete homogeneity. The samples were kept in air tight containers until the time of paste preparation. Blended cement pastes were prepared using the required water of consistency ${ }^{(49)}$.

Using a trowel, the amount of water and cement has been mixed for four minutes. The pastes has directly been poured in a cubic mold 2 X 2 X $2 \mathrm{~cm}$ and pressed until ahomogenous specimen has been obtained. The molds were vibrated to remove any air bubbles. The surface of the pastes was smoothed by spatula.

\section{Curing time}

For the first $24 \mathrm{hr}$ the specimens were cured with their molds in $100 \%$ relative humidity. The cubic specimens were removed from their molds and then cured under tap water, at room temperature, until the time of testing $(3,7$, 28 and 90 days).

TABLE 2. Mix compositions of the prepared blended cements mass \%.

\begin{tabular}{|c|c|c|c|c|}
\hline Mix no. & OPC & BS & NS & Water/g \\
\hline M0 & 100 & 0 & 0 & 27 \\
M1 & 95 & 5 & 0 & 27 \\
M2 & 90 & 10 & 0 & 27.2 \\
M3 & 85 & 15 & 0 & 27.4 \\
M4 & 80 & 20 & 0 & 27.5 \\
M5 & 80 & 19 & 1 & 28 \\
M6 & 80 & 18 & 2 & 28.3 \\
M7 & 80 & 17 & 3 & 28.5 \\
M8 & 80 & 16 & 4 & 29.1 \\
\hline
\end{tabular}

\section{Experimental test}

Measurements of bulk density, compressive strength and stopping of hydration

Bulk density measurements: The bulk density was measured at each selected curing age before the specimens are subjected to the compressive strength determination. Each measurement was conducted on at least three similar cubes of the same mix composition and curing time ${ }^{(50)}$.

Compressive strength measurements: The compressive strength was determined according to (ASTM Designation: C-150, 2007) ${ }^{(51)}$. At each time interval, three cubes of each hardened cement paste were subjected to compressive strength test and the average value was recorded. This was accomplished by using a Ton-industries machine (West Germany) for a maximum

Egypt. J. Chem. 59, No.4 (2016) 
load of 60 tons. The resulting crushed specimens of the hardened cement pastes were ground and the hydration reaction was stopped ${ }^{(52)}$.

Stopping of hydration:The hydration of cement pastes was stopped by pulverizing the crushed and ground specimens in a beaker containing1:1(v/v) methanol - acetone mixture. Then,mechanically stirred for $1 \mathrm{hr}$, the mixture was filtered through sintered glass G4 after having been washed two times by the stopping solution and diethyl ether. Then,the paste has been dried at $80^{\circ} \mathrm{C}$ for $1 \mathrm{hr}$ and collected in polyethylene bags, sealed and stored in desiccators for analysis $^{(52)}$.

\section{Determination of combined water content}

The chemically combined water content, $\left(\mathrm{W}_{\mathrm{n}}, \%\right)$, was determined by the ignition loss test at $1000^{\circ} \mathrm{C}$ for $1 \mathrm{hr}$. Duplicate measurements were carried out for each sample and the mean value was recorded ${ }^{(53)}$.

\section{Free lime (portlandite) determination}

Free lime (portlandite) content, $\mathrm{CaO}(\%)$ was determined by using the glycerol/ ethanol extraction method and the mean value of the two independent determination was recorded ${ }^{(50,53)}$.

\section{$X$ - ray diffraction analysis}

X-ray diffraction (XRD) of some selected hydrated samples has been investigatedusing Philips diffract meter PW 1730,with X-ray source of $\mathrm{Cu} \mathrm{k}_{\alpha}$ radiation $\left(\lambda=1.5418 \mathrm{~A}^{0}\right)$. The scan step size was $2 \theta$, the collection time $1 \mathrm{~s}$ and in the range of $2 \theta$ from 5 to $65^{\circ}$. The tube voltage and current of the X-rayhave been fixed at $40 \mathrm{kv}$ and $40 \mathrm{~mA}$,respectively. An on-line search of standard data base (JCPDS database) foran X-ray powder diffraction pattern enables phase identification for a large variety of crystalline phases in a sample ${ }^{(54)}$.

\section{Differential thermal analysis (DTA).}

The ground hydrated specimens were investigated using a differential thermal analyzer (DTA) of type Instrument: Q600 - SDT simelleousTG DSC -USA V20.5Build 15. The DTA runs were carried out for the hydrated powdered samples from the ambient temperature up to $1000^{\circ} \mathrm{C}$ at a heating rate of $10^{\circ} \mathrm{C} /$ min using $\alpha \mathrm{Al}_{2} \mathrm{O}_{3}$ as reference sample.

\section{Results and Discussion}

\section{Characteristics of OPC- basalt blended cement pastes}

Chemically combined water content

The degree of hydration is measured from the chemically combined water and free portlandite contents. The results of the chemically combined water content for all hydrated blended basalt cement pastes investigated, neat OPC and OPC- BS are given in Fig. 1. It can be seen that the values of combined water content increase as long as the period of hydration prolongs. This is true 
for all hardened pastes made of all mixes, up to the final time of hydration (90 days). This increase can be attributed to the progress of the hydration reaction and the formation of more excessive amounts of hydrated products, which are deposited in the available open pores of the hardened cement pastes. The combined water content of all blended basalt cement pastes is lower than that of Portland cement pastes. This is due to the decrease of clinker content and the low pozzolanic activity of basalt ${ }^{(39,55)}$.

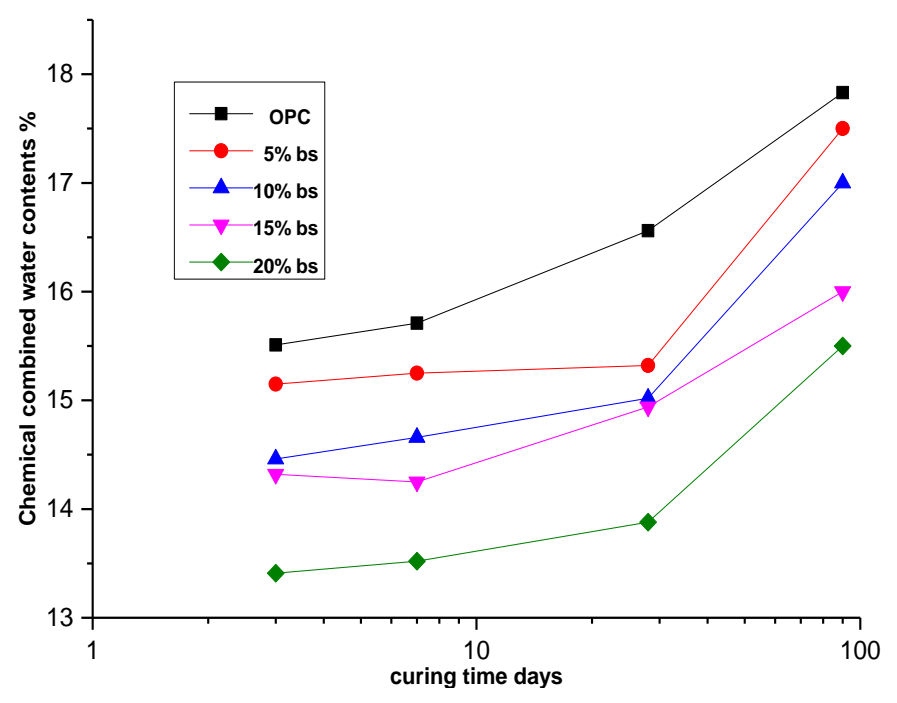

Fig.1. Combined water contents of hydrated cement pastes containing basalt against curing time.

Free lime content

Free lime (portlandite) contents for the various investigated neat OPC and blended basalt cement pastes are shown in Fig. 2. The results show that the free lime contents increase continuously when the period of hydration is prolonged. This is true for the neat OPC and the basalt cement pastes. This means that basalt behaves as filler, so this type of cement is called filled cement. The observed free lime contents for blended basalt cement pastes increase as the amount of basalt increases up to 15 mass \% basalt up to the age of hydration. The increase of free lime with amount of basalt may be due to the nucleating effect of basalt which accelerates the rate of hydration of cement pastes. At20 mass \% basalt, the free lime is lower than that of 15 mass \% basalt at all hydration times. This is mainly due to the decrease of the amount of Portland cement, which is the main source of liberated $\mathrm{CH}$. Blended cement pastes with 20 mass \% basalt show an increase in free lime up to 28 days followed by a marked decrease after 90 days. Evidently, the values of free lime content represent a net result of two opposite processes. The first is an increase in the

Egypt. J. Chem. 59, No.4 (2016) 
amount of $\mathrm{CH}$, which is liberated from hydration of OPC; and the second is the consumption of these liberated $\mathrm{CH}$ via pozzolanic reaction with basalt and the formation of additional calcium-silicate and calcium alumino - silicate hydrates $(\mathrm{CASH})^{(38,39,55)}$.

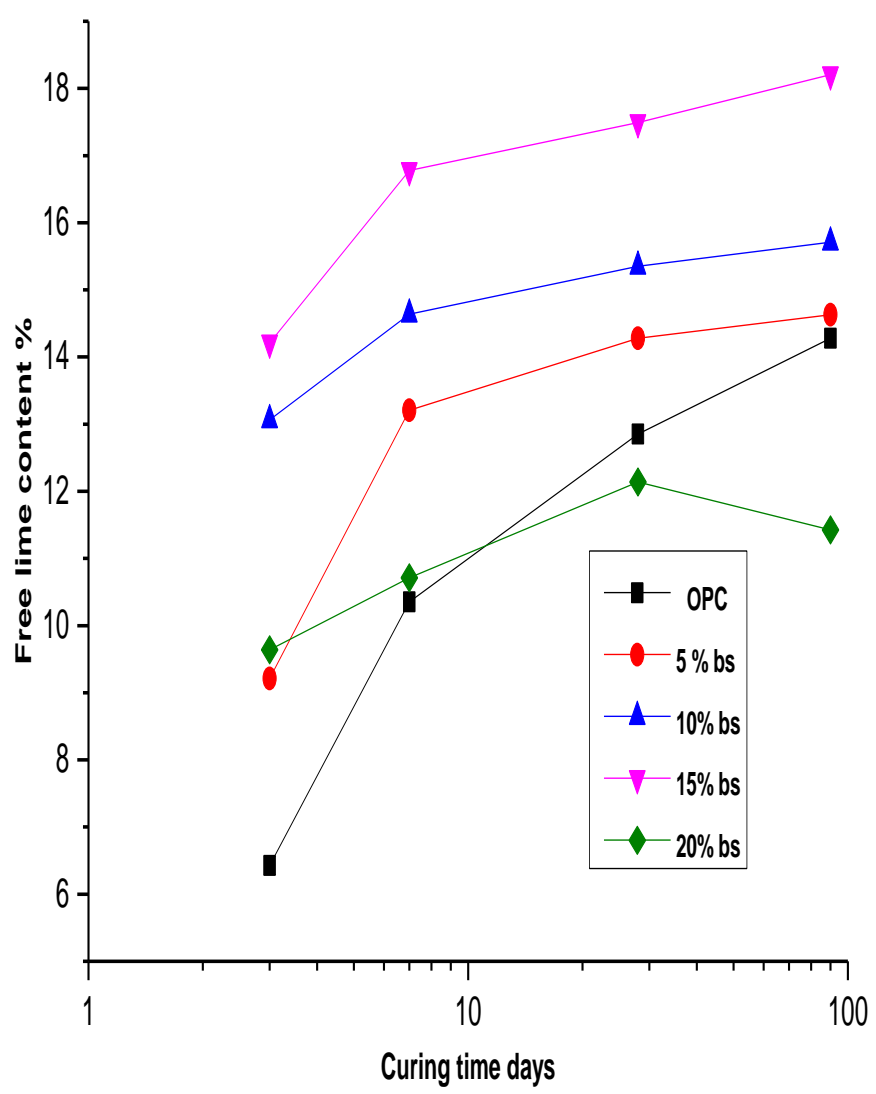

Fig.2. Free lime contents of hydrated cement pasts containing .

\section{Bulk density}

The results of bulk density of neat OPC and blended basalt cement pastes are given in Fig. 3. It is clear that the bulk density increases in accordance with the hydration time as well as the amount of basalt increases up to 15 mass \% $\left(\mathrm{M}_{3}\right)$ than those of OPC pastes. This increase is because basalt acts as an ucleating agent which accelerates the hydration of cement pastes and basalt acts as a filler which increases bulk density. 20 mass \% basalt gives lower bulk density than 15 mass \% basalt. This is mainly due to the decrease of the amount of OPC which has good hydration products in comparison to basalt which has little pozzolanic activity $(39,40)$. 


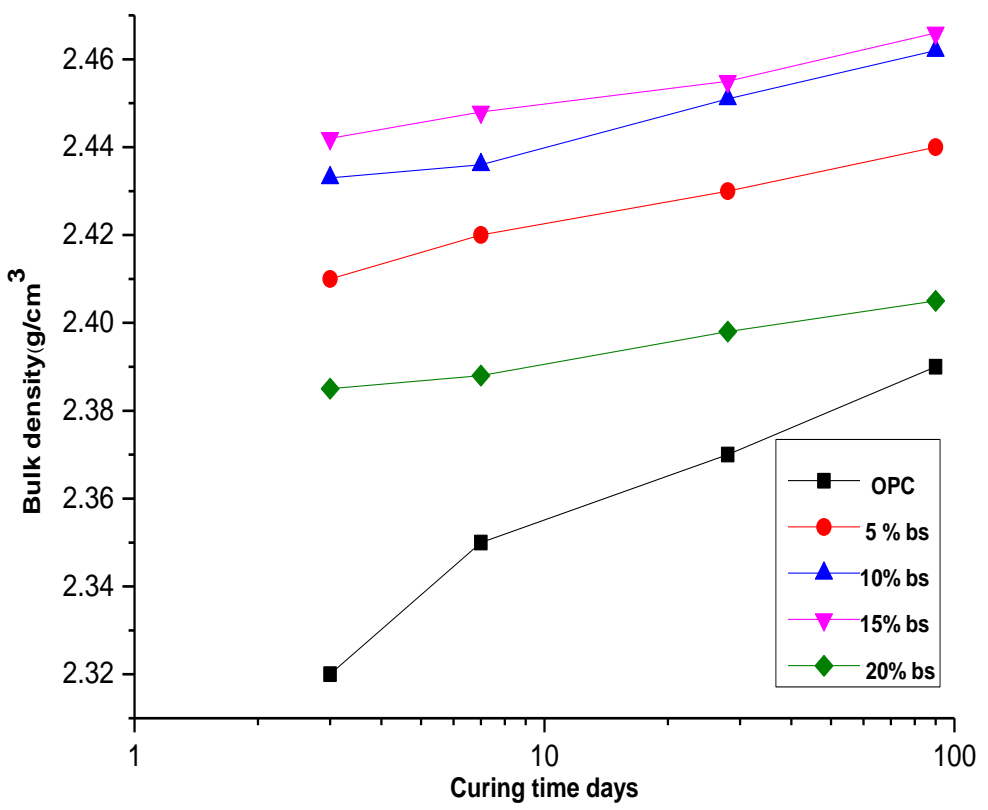

Fig. 3. Bulk density of hydrated cement pasts containing bagainst curing time .

\section{Compressive strength}

The results of compressive strength values of both the hardened pastes, made of neat OPC, and blended basalt cement pastes are shown in Fig. 4. Evidently, the values of compressive strength of the neat and blended cement pastes increase continuously in accordance with the time of hydration up to 90 days ${ }^{(46,56)}$. As the hydration proceeds, more hydration products and more cementing materials are formed leading to an increase in the compressive strength of cement pastes. This is mainly because the hydration products possess a large specific volume than the unhydrated cement. Therefore, the accumulation and compaction of these hydrated products are formed with a higher strength. The compressive strength of pozzolanic cement pastes is lower than that of OPC due to the dilution effect of pozzolana and the slow rate of pozzolanic reaction ${ }^{(38,40)}$.

Characteristics of OPC- basalt- nanosilica (OPC-BS-NS) composite cement pastes

Chemically combined water content $\left(W_{n}\right)$

The results of chemically combined water content $\left(\mathrm{W}_{\mathrm{n}}, \%\right)$ for all composite cement pastes containing different percent of NS hydrated up to 90 days are given in Fig.5. The results show that $\mathrm{W}_{\mathrm{n}}$ increases as the hydration time progresses, and this reflects the increases of the rate of the hydration reaction for OPC-BS- NS composite cement. The values of $\mathrm{W}_{\mathrm{n}}$ increases in accordance with the increasing content of NS due to the high pozzolanic activity of NS and

Egypt. J. Chem. 59, No.4 (2016) 
the increase of therequired mixing water. Faster formation of $\mathrm{CH}$ during the initial period and the acceleration of the hydration of cement pastes were observed in the NS added cement pastes ${ }^{(5)}$. Due to the reaction of NS withthefaster formed portlandite, the amount C-S-H gel increases ${ }^{(22,25)}$. NS particles accelerate the hydration of cement phases, especially at early ages of hydration, because they serve as nucleation sites for the growth of C-S-H, (C-A$\mathrm{H})$ and $\mathrm{C}-\mathrm{A}-\mathrm{S}-\mathrm{H}^{(5,6)}$.

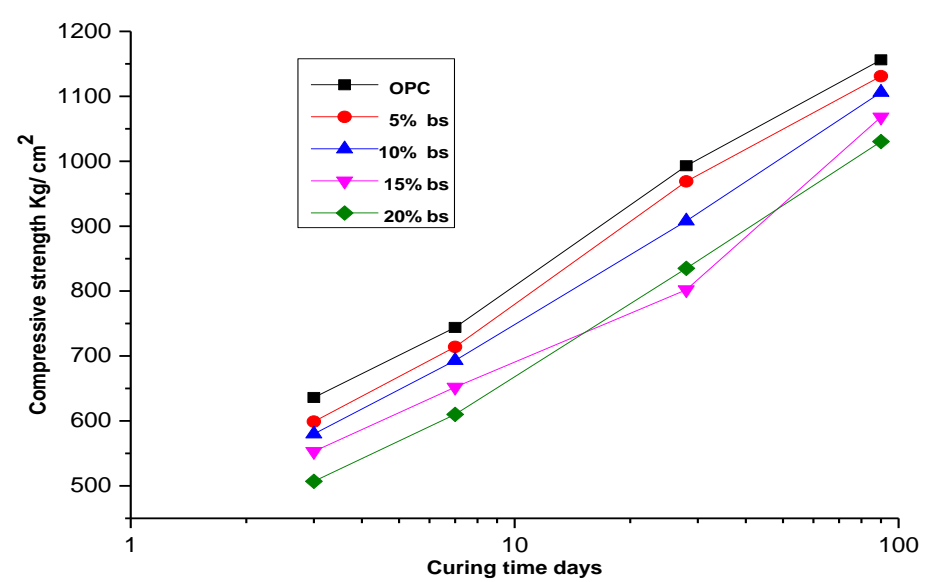

Fig.4. Compressive strength of hydrated cement pasts containing basalt against curing time .

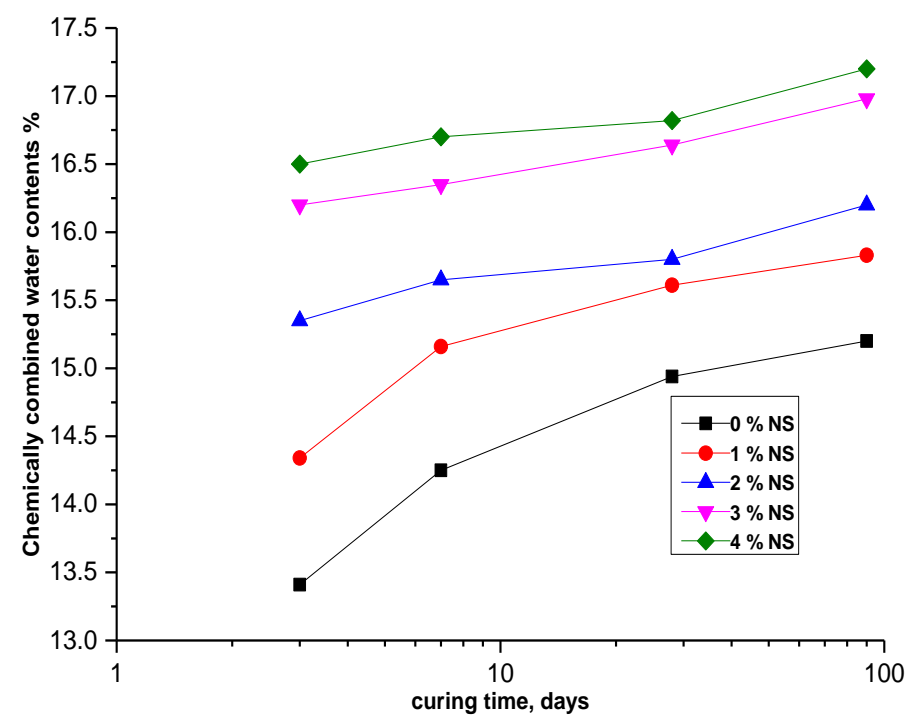

Fig.5. Combined water contents blended basalt cement pasts containing NS against curing time .

Egypt. J. Chem. 59, No.4 (2016) 


\section{Free lime content}

The variation of free lime contents of cement pastes containing different percentage of NS hydrated up to 90 days are shown in Fig.6. It is obvious that free lime contents decrease with curing time for all cement pastes. The decrease of free lime of the hydrated cement pastes containing NS with curing time is attributed to the rapid pozzolanic reaction between NS and the liberated $\mathrm{CH}$ in addition to the formation of calcium silicate and calcium alumino - silicate hydration ${ }^{(26)}$. At 90 days, free lime decreases sharply due to the high pozzolanic activity of NS and low pozzolanic activity of basalt at later ages. As the NS content increases, the values of free limedecrease.This is due to the higher pozzolanic affinity of NS in comparison with basalt ${ }^{(3,57)}$. NS particles show typical characteristics of a cement hardening accelerator ${ }^{(6)}$. Their efficiency depends on the particle surface area on one hand, and on the pozzolanic reactivity on the other hand ${ }^{(6)}$.

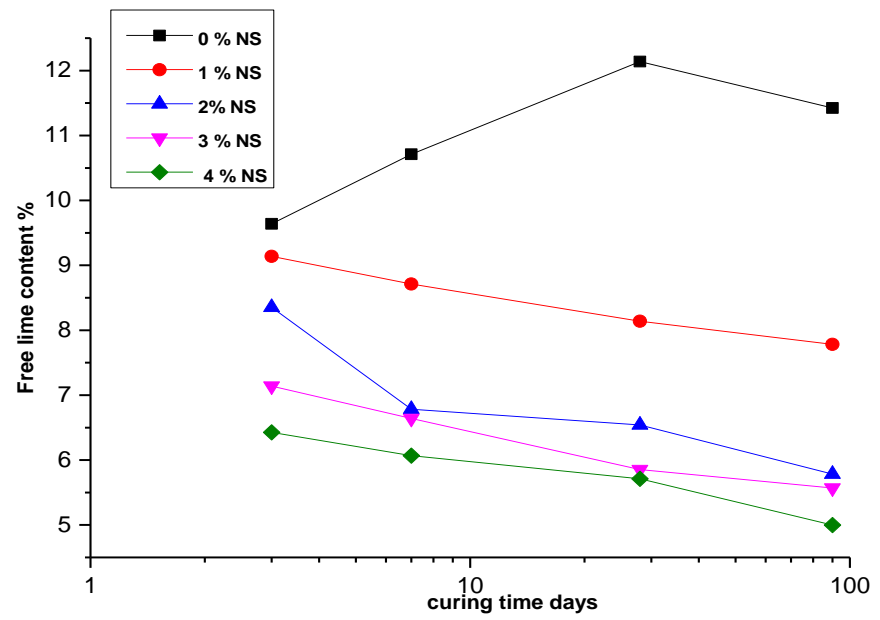

Fig. 6. Free lime contents of blended basalt cement pastes containing basalt NS against curing time.

\section{Bulk density}

Variation of bulk density of hardened basalt cement pastes containing different percentage of NS hydrated up to 90 days is graphically represented in Fig. 7. It is clear that the bulk density increases with curing time for all hydrated cement pastes due to the continuous hydration of cement phases, leading to the formation and accumulation of additional amounts of hydrated $\mathrm{CSH}$ and $\mathrm{CASH}$ which tends to increase the gel/ space ratio leading to a homogenous and closed compact structure ${ }^{(52,58)}$. The results show also that the bulk density of the investigated samples decreases in accordance with the increasing content of NS. The decrease in bulk density can be attributed to the replacement of denser basalt particle $\left(2.8-3 \mathrm{~g} / \mathrm{cm}^{3}\right)$ with lighter NS particles $\left(2.21 \mathrm{~g} / \mathrm{cm}^{3}\right)^{(13,59)}$. It is clear that all pozzolanic blended basalt cement containing NS has a bulk density lower than that of control paste as a result of the dilution effect of pozzolanic materials.

Egypt. J. Chem. 59, No.4 (2016) 


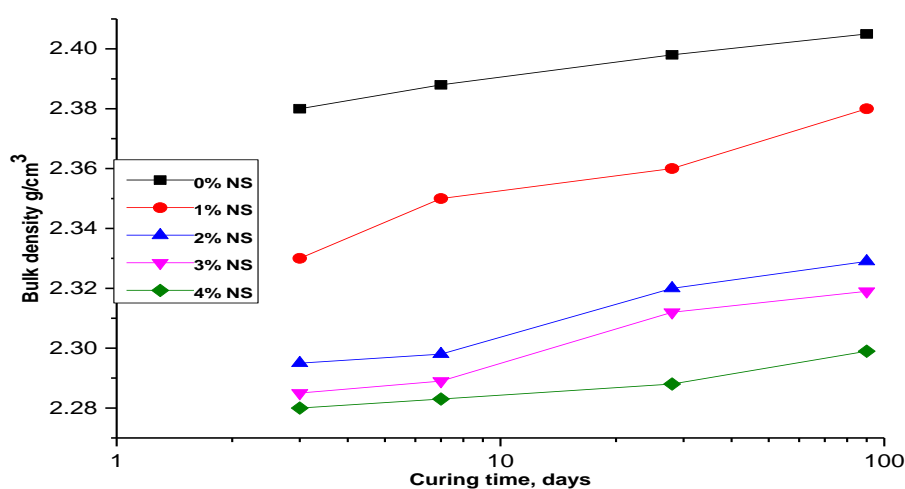

Fig.7. Bulk density of blended basalt cement pastes containing NS against curing time .

Compressive strength

The test data for compressive strength of blended basalt cement pastes containing different dosages of NS cured up to 90 days are given in Fig. 8. For all (OPC- BS - NS) composite cement pastes, the values of compressive strength increase with curing time; this is due to the continous hydration and formation of excessive amount of C-S-H and alumino - silicate hydrates. These products accumulate in the available open pores to form a more compact closed structure body ${ }^{(2,27)}$. NS has produced a significant improvement of compressive strength for blended cement pastes at early and later ages ${ }^{(5,27)}$. Several studies have showed that the application of NS in cementitious systems increases the strength development, especially at the early age of hydration ${ }^{(5,9,22,31)}$.

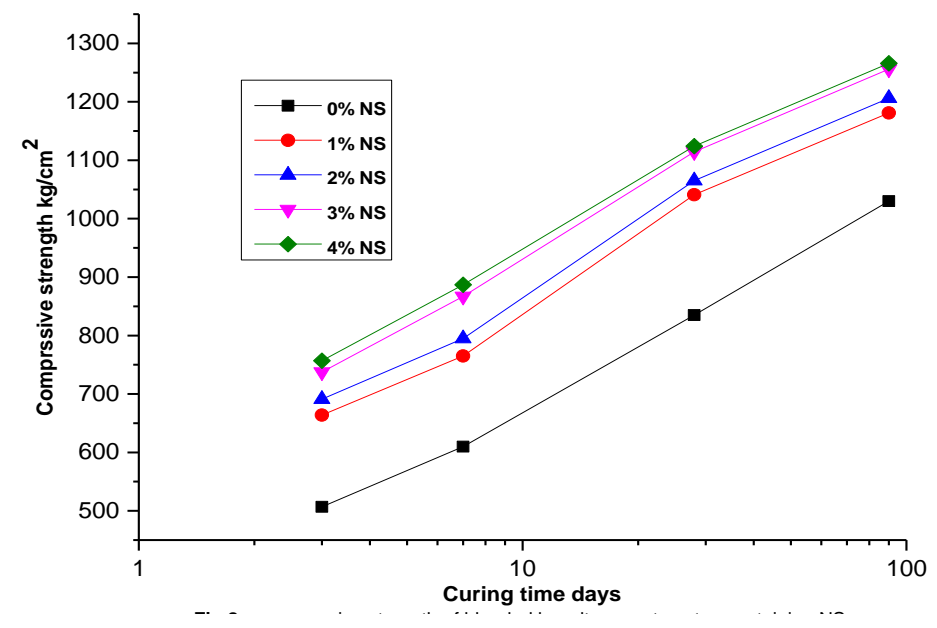

Fig. 8. Compressive strength of blended basalt cement pastes containing NS against curing time.

Egypt. J. Chem. 59, No.4 (2016) 
The results showed also that the compressive strength of the investigated basalt cement pasts increases with NS up to $3 \%$ then increase slightly up to $4 \%$. It was observed that the strength values of all blended basalt cement containing NS are higher than those of hardened blank cement pastes at all curing periods. From the results it has been indicated that substitution of $3 \% \mathrm{NS}\left(\mathrm{M}_{7}\right)$ increases the compressive strength( in compression to control sample) at ages of 3 days and 90 days by $31 \%$ and $18 \%$, respectively. On the other hand an increase of NS content from $3 \%$ to $4 \% \mathrm{NS}\left(\mathrm{M}_{8}\right)$ enhances the compressive strength at the ages of 3 days and 90 days by $2.6 \%$ and $1.5 \%$, respectively. These values indicate that the improvements of compressive strength at the early age are higher than those at later ones. On the other hand, as the NS content increases (from $3 \%$ up to $4 \%$ ) there is no great difference in compressive strength. Generally, the improvement of compressive strength in presence of NS can be attributed to some reasons: (i) NS works as fillers in the spaces of the grains to improve the microstructure, (ii) The surface of NS particles acts as a nucleation site for CSH seeds, which then accelerate the cement hydration and lead to the growth of the hydration products ${ }^{(5)}$, (iii) NS particles behave as an activator to promote the highly pozzolanic reaction and allow an increase in the quantity of C-S-H, C-A-S-H (the main source of compressive strength) ${ }^{(2,15)}$ and (iv) The small particle size of NS and a large value of surface area have a major factor for the kinetics of hydration reactions ${ }^{(6,27)}$.

$X$-ray diffraction analysis $(X R D)$

Figure 9 shows XRD patterns of the blended cement pastes made of $20 \%$ basalt hydrated up to 90 days. As shown in Fig.9, the intensities of the peaks characteristics of $\mathrm{CH}$ increase gradually during the early age of hydration for OPC- basalt pastes up to 28 days; this increase is attributed to the amount of $\mathrm{CH}$ liberated from OPC hydration. This indicates that basalt acts asfiller up to this time of hydration. On the other hand, at the later age of hydration (90 days) the amount of $\mathrm{CH}$ consumed in the pozzolanic reaction with basalt exceeds the amount of liberated during OPC hydration. So, there will be a net decrease in the amount of $\mathrm{CH}$ leading to a decrease in the intensities of the peaks characterizing $\mathrm{CH}$ after 90 days of hydration. There are some remaining anhydrous parts of $\beta \mathrm{C}_{2} \mathrm{~S}, \mathrm{C}_{3} \mathrm{~S}$ and calcite. The hydration products are mainly $\mathrm{C}$ $\mathrm{S}-\mathrm{H}, \mathrm{C}-\mathrm{A}-\mathrm{H}$ and C-A-S-H ${ }^{(38-40)}$.

Figure 10 shows XRD patterns ofOPC and blended basalt cement pastes $\mathrm{M}_{2}$ (10 mass \% basalt) and $\mathrm{M}_{3}$ (15 mass \%basalt) hydrated for 28 days. Evidently, the hydration products are mainly calcium silicate hydrates (C-S-H) and portlandite in addition to the remaining parts of $\beta-C_{2} S$ and $C_{3} S$ grains. The intensities of $\mathrm{CH}$ peaks increase with basalt addition. This may be due to the rehydration of some decomposed portlandite and the nucleating function ofbasalt which accelerates the hydration of cement ${ }^{(38,39)}$. 


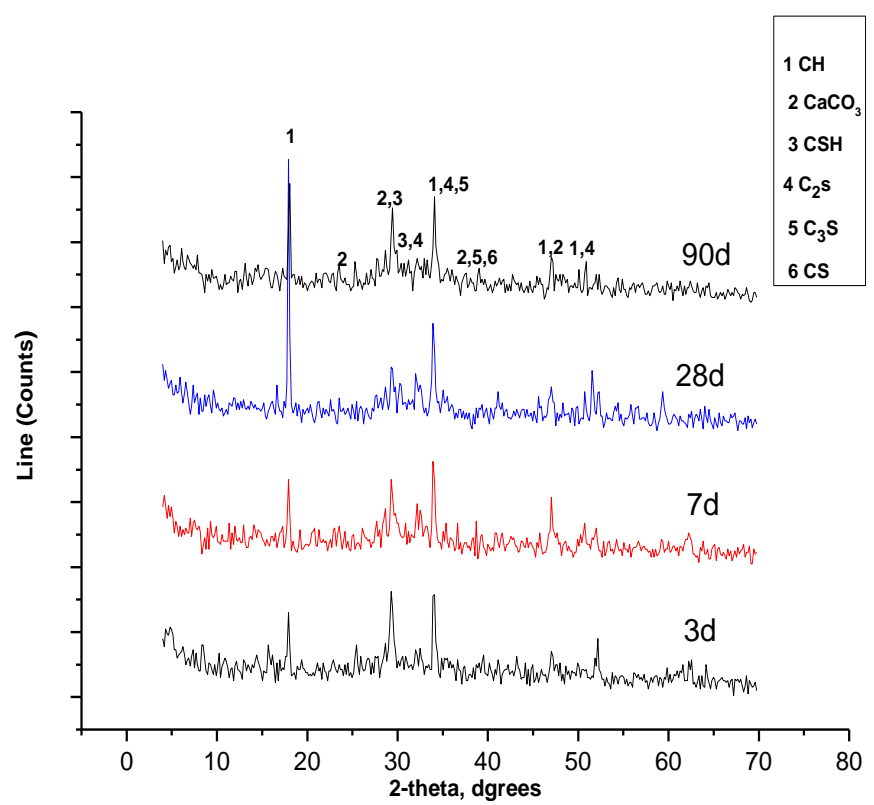

Fig.9. X-ray diffraction analysis of cement pastes containing 20 wt $\%$ basalt cured up to 90 days. .

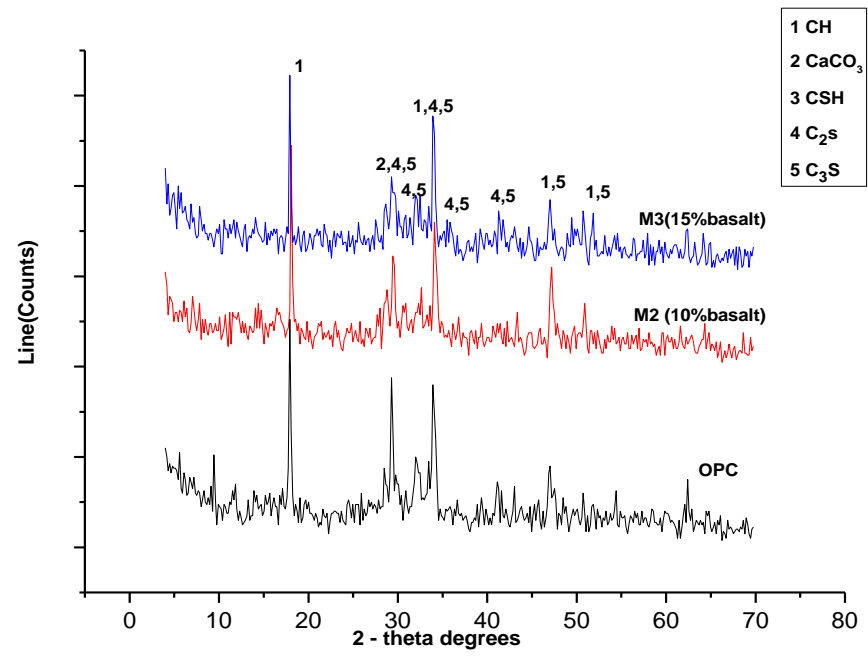

Fig.10. X-ray diffraction analysis of OPC, M2(10\%) and M3 (15\%) blended basalt cement pasted hydrated for 90 days. 
Figure 11 shows XRD patterns of OPC pastes as well as blended basalt cement pastes containing different mass \% of NS hydrated for 90 days. Cement pastes containing NS showed lower intensity of the characteristic peaks corresponding to $\mathrm{CH}$ and higher intensity of diffraction lines characteristics for $\mathrm{CSH}$ than those of the corresponding peaks of the control mix .The intensity of $\mathrm{CH}$ peak as well as anhydrous silicate phases $\left(\beta \mathrm{C}_{2} \mathrm{~S}\right.$ and $\left.\mathrm{C}_{3} \mathrm{~S}\right)$ decrease when the NS content increases. This behavior is a result of the high pozzolanic activity of NS and the pozzolanic reaction of NS with $\mathrm{CH}$, which allows an increase in the quantity of $\mathrm{CSH}^{(10,17,27)}$.

Figure 12. investigates the X- ray patterns of blended basalt cement pastes containing 3 mass $\%$ of NS hydrated up to 90 days. Senff et al ${ }^{(13)}$ observed the presence of $\mathrm{CH}$ in sample with NS at $9 \mathrm{hr}$. XRD shows the presence of $\mathrm{CH}$ already after 3 days which contributes to the increased production of $\mathrm{CH}$ at early ages. The results show that the peaks of $\mathrm{CH}$ and anhydrous silicate phases decrease with the curing time progresses. This is due to the progress of hydration reaction and the pozzolanic reaction of NS with the liberated $\mathrm{CH}$ leading to the formation of additional amounts of hydrated calcium silicates ${ }^{(10)}$.

\section{Differential thermal analysis}

DTA curves of the hydrated samples of neat OPC and specimens containing 10 mass $\%$ and 15 mass \% of basalt hydrated for 28 days are given in Fig. 13. The curves illustrate three endotherms at $150-200,400-500,700-800^{\circ} \mathrm{C}^{(54)}$. The first endothermic peak is due to the decomposition of CSH as well as CAH. The second endothermic peak located at $400-500^{\circ} \mathrm{C}$ which represents the major weight loss is mainly related to the decomposition of portlandite. In addition, the third peak is due to the decomposition of $\mathrm{CaCO}_{3}$. The peak area of C-S-H and $\mathrm{C}-\mathrm{A}-\mathrm{H}$ decreases with the amount of basalt. This means that the basalt is a filler which accelerates the rate of hydration of cement pastes. The peak area of $\mathrm{Ca}(\mathrm{OH})_{2}$ increases with basalt content and this is because basalt acts as a nucleating agent ${ }^{(55)}$.

DTA curves in Fig. 14 showing composite cement pastes containing 3 mass \% NS hydrated up to 90 days indicate various endotherms at about 150-190, 400500 , and $700-800^{\circ} \mathrm{C}$. The first peak at $150-190^{\circ} \mathrm{C}$ is due to the dehydration, dehydroxlation, decomposition of $\mathrm{CSH}, \mathrm{CAH}, \mathrm{CASH}$. These peaks are explained in terms of increasing amounts of the formed hydrates. The second peak, located at $400-500{ }^{\circ} \mathrm{C}$, is related to the decomposition of portlandite $(\mathrm{CH})$. The peak of $\mathrm{Ca}(\mathrm{OH})_{2}$ decreases when the period of hydration increases. This is due to the consumption of free $\mathrm{CH}$ by the pozzolanic reaction with NS. The third peak, located at $700-800^{\circ} \mathrm{C}$, is related to the carbonation of some $\mathrm{Ca}(\mathrm{OH})_{2}$ during handling of crushed samples ${ }^{(54)}$. 


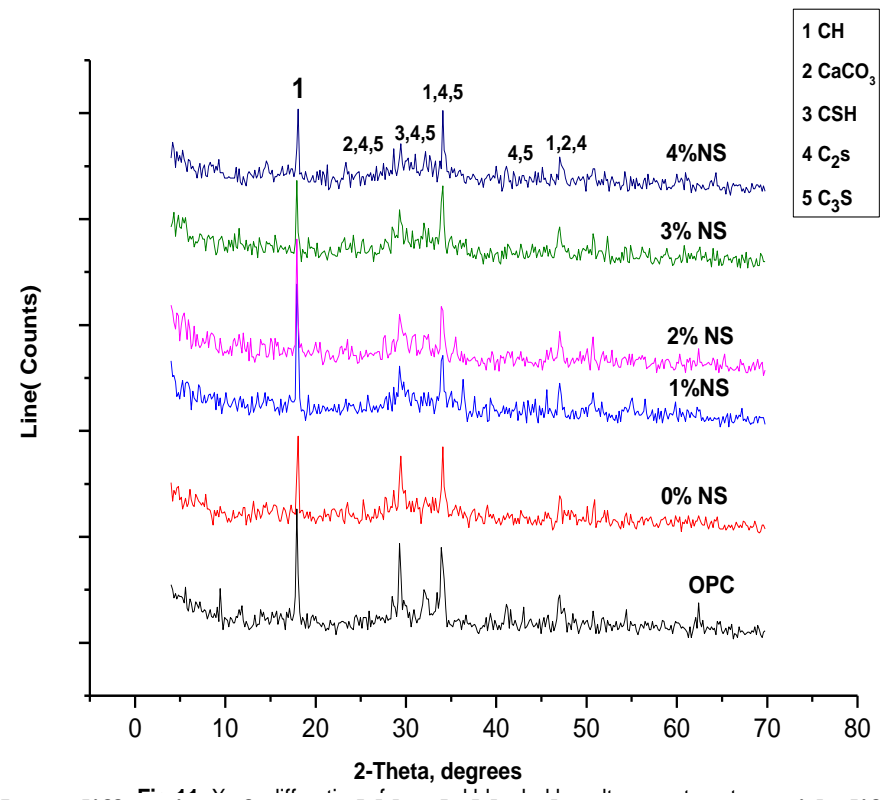

Fig.11. X-ray diffraction of opc and blended basalt cement pastes with different NS contents hydrated for 90 days.

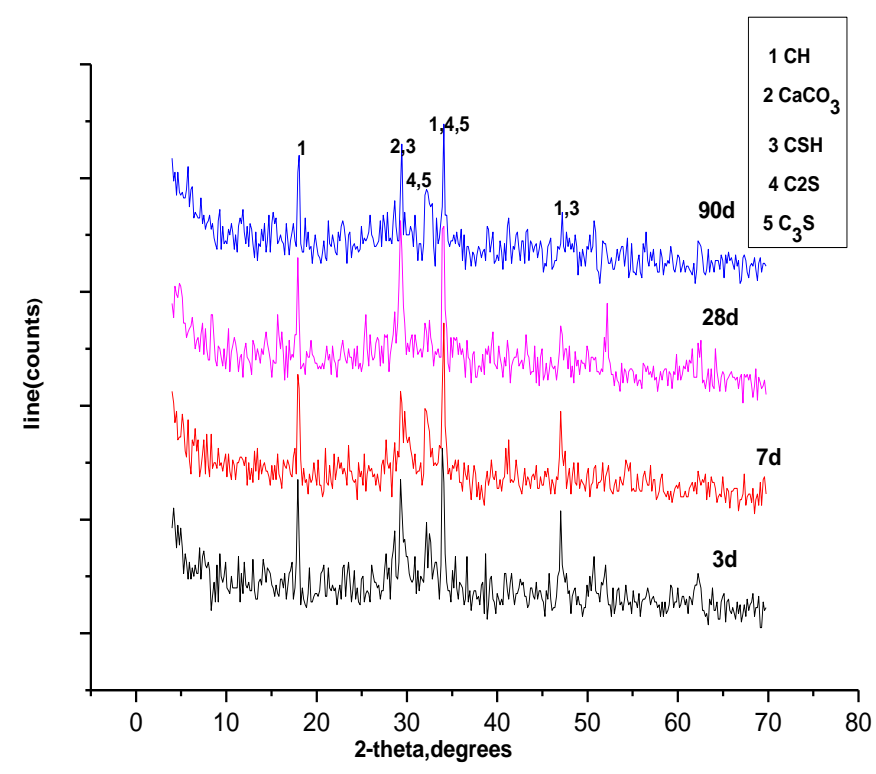

Fig.12. X-ray diffraction of blended basalt cement containing 3\% NS hydrated up to 90 days. 


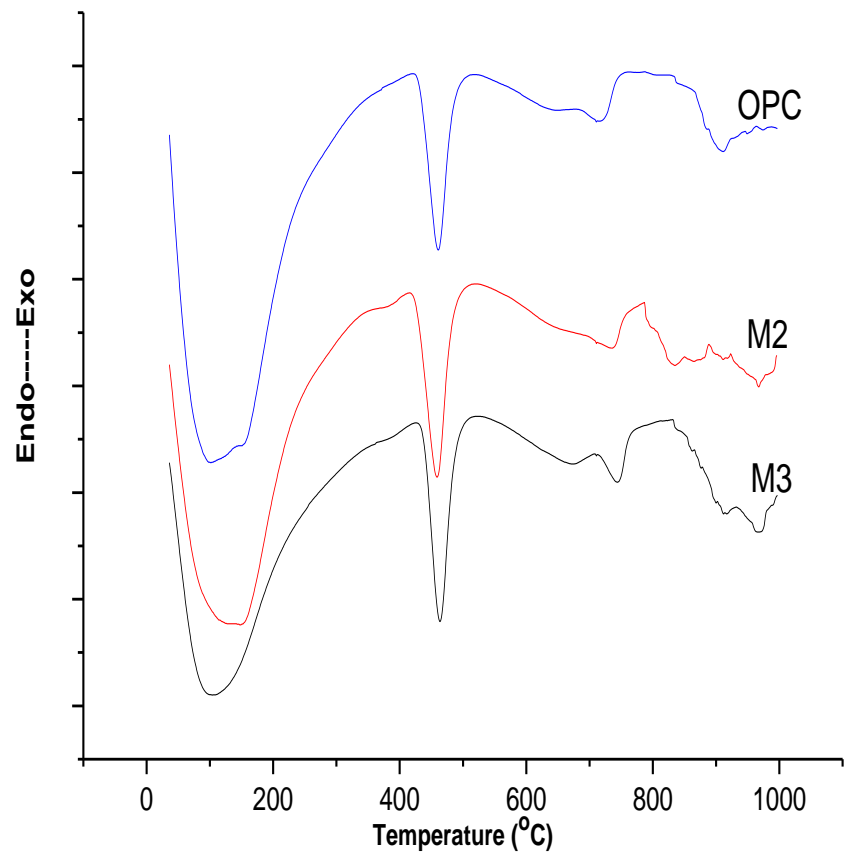

Fig.13. DTA diagrm of OPC, M2 $(10 \%)$, M3 (15\%) of blended basalt cement pasteshdrated for 28 days.

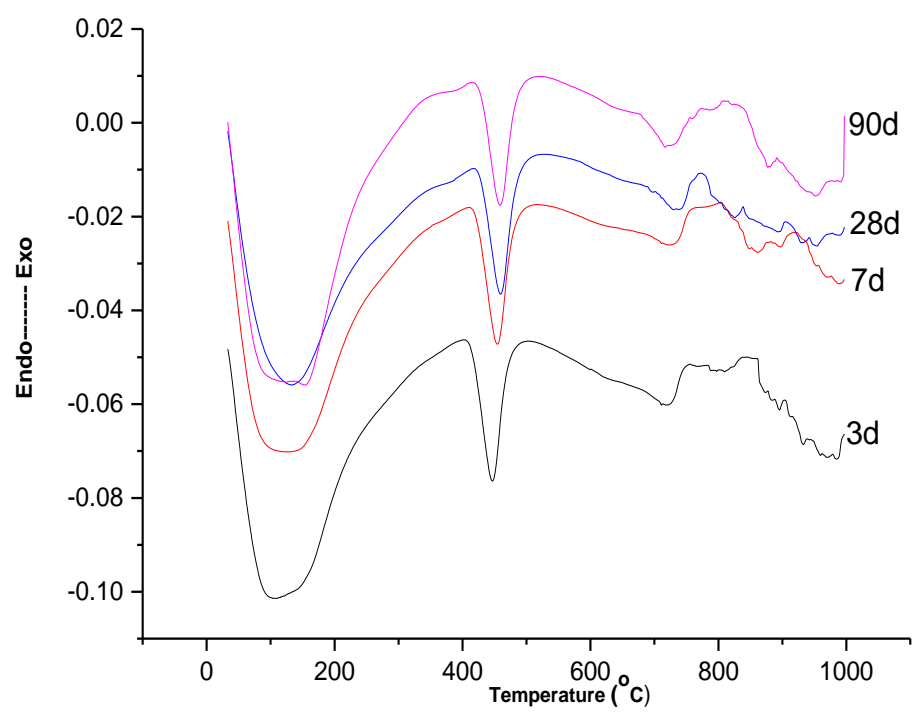

Fig.14. DTA diagrm of blended basalt cement pastes containing $3 \%$ NS cured up to 90 days.

Egypt. J. Chem. 59, No.4 (2016) 
The above mentioned discussion can be extended to the DTA curves represented in Fig.15. Figure 15 represents the DTA curves of neat OPC and hydrated mixes containing different mass \% of NShydrated for 90 days. The results illustrate the increase and decrease of all above mentioned peaks for different mixes hydrated for 90 days. The results show that the endothermic peak corresponding to CSH of OPC has a lower intensity than those of all mixes containing NS cement pastes. Peak area of $\mathrm{CSH}$ and $\mathrm{CSAH}$ increases in accordancewith theamount of NS substituting that of basalt. This is due to the higher pozzolanic activity of NS in comparison to basalt. Peak area of $\mathrm{CH}$ decreases withNS. This is mainly due to the pozzolanic reaction of NS with the liberated lime during cement hydration. It is clear that the rate of pozzolanic reaction increases when the content of NS increases with increasing NS content. The results of DTA are in a good agreement with those of XRD and chemical analysis.

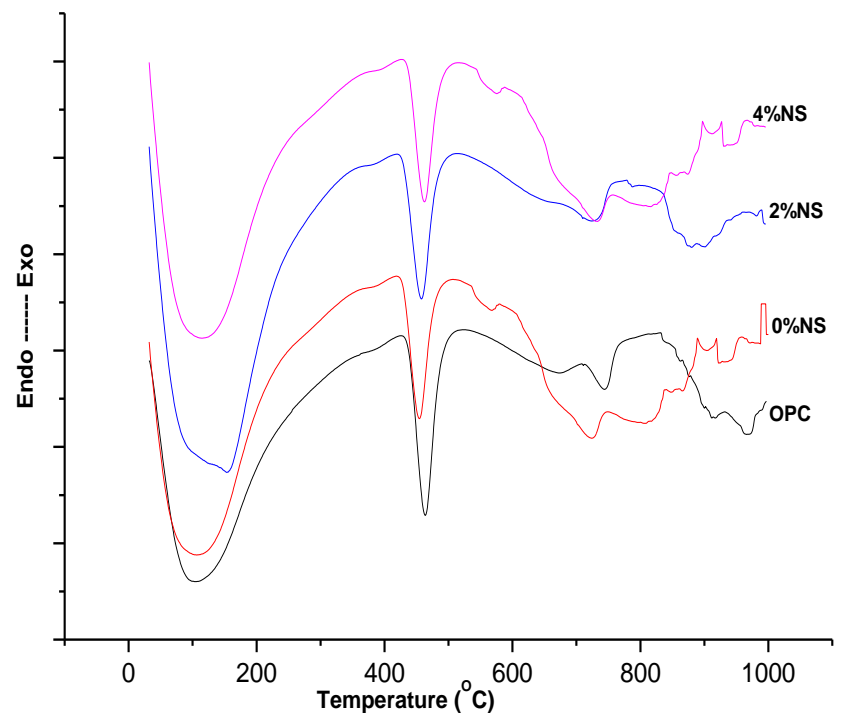

Fig.15. DTA of OPC and blended basalt cement pastes with different NS contents cured for 90 days.

\section{Conclusions}

The main points of this paper can be outlined as follows:

[1] Basalt can be used as a filled-pozzolanic material.

[2] The substitution of OPC for basalt leads to a decrease in the compressive strength.

[3] NS particles accelerate the hydration of blended basalt cement pastes.

[4] At all curing ages, the compressive strength generally increases when NS is added up to $4 \%$. 
[5]The substitution of blended basalt cement pastes for 3 mass $\%$ NS increases the compressive strength at ages of 3days and 90days by $31 \%$ and $18 \%$, respectively.

[6] As the NS content increases (from 3 mass \% up to 4 mass \%), there is no great difference in compressive strength.

[7] Results showed that the combined water of blended basalt cement pastes increases and free portlanditedecreases when adding NS.This indicates that the ultrafine nature of NS was responsible for speeding up the kinetic of hydration reactions.

[8] XRD and DTA proved that more hydration products are formed in the presence of NS.

\section{Recommendation:}

Further studies may be needed to examine the performance of nanomaterials, such asnanosilica, nanoalumina, as a good additions to Portland cement. There are many questions about their performance and method of use due to their chemical, physical and mineralogical characteristics.

\section{References}

1. Thomas, J.J., Jennings, H.M. and Chen, J.J., Influence of nucleation seeding on the hydration mechanisms of tricalcium silicate and cement. J. Phys. Chem. C 2009; 113, 4327- 34 .

2. Sobolev, K. and Gutierrez, M.F., How nanotechnology can change the concrete world - Part one. Am Ceram Soc Bul.l 84, 14- 7 (2005).

3. Jo B, Kim C, Tae G. and Park J., Characteristics of cement mortar with nano- $\mathrm{SiO}_{2}$ particles. Constr . Build Mater. 21, 1351-5 (2007).

4. Korpa, A., Trettin, R., Bttger, K.G., Thieme, J. and Schmidt, C., Pozzolanic reactivity of nanoscalepyrogene oxides and their strength contribution in cementbased systems. Adv. Cem. Res. 20, 35-46 (2008).

5. Land, G. and Stephan, D., The influence of nano-silica on the hydration of ordinary Portland cement. J. Mater. Sci. 47,1011- 7 (2012)

6. Land, G. and Stephan, D., Controlling cement hydration with nanoparticles. Cement and Concrete Compos. 57, 64-67 (2015).

7. Min-Hong, Z., Jahidul, I. and Sulapha, P., Use of nano-silica to increase early strength and reduce setting time of concretes with high volumes of slag. Cem. Concr . Compos .34 (5), 650- 62 (2012).

8. Berra, M., Carassiti, F., Mangialardi, T., Paolini, A.E. and Sebastiani, M.,Effects of nanosilica addition on workability and compressive strength of Portland cement pastes. Constr.Build Mater. 35, 666-75 (2012) 
9. Tobon J.I., Restrepo J. and Paya J., Comparative analysis of performance of Portland cement blended with nanosilica and silica fume. DYNA; 163, 37-46(2010)

10. Nazari, Ali and Riahi Shadi., The effects of $\mathrm{SiO} 2$ nanoparticles on physical and mechanical properties of high strength compacting concrete. Compos. Part B, 42,570- 8. (2011).

11. Ltifi Mounir, Guefrech Achraf, Mounanga Pierre and Khelidj Abdelhafid, Experimental study of the effect of addition of nano-silica on the behaviour of cement mortars. Procedia Eng. 10, 900- 5. (2011).

12. Naji Givi A., Abdul Rashid, S., Nora A., Aziz, F. and Amran Mohd Salleh M., The effects of lime solution on the properties of $\mathrm{SiO} 2$ nanoparticles binary blended concrete. Compos. Part B 42, 562- 9. (2011).

13. Senff, L., Joao, A.L., Victor, M.F., Dachamir, H. and Wellington, L.R., Effect of nano-silica on rheology and fresh properties of cement pastes and mortars. Constr. Build Mater. 23(7):2487-91(2009).

14. Said, A.M., Zeidan, M.S., Bassuoni, M.T. and Tian Y., Properties of concrete incorporatingnano-silica. Constr. Build Mater. 36, 838- 44. (2012).

15. HouPeng-kun, Kawashima Shiho, Wang Ke-jin, Corr David J, Qian Jue-shi and Shah Surendra P., Effects of colloidal nanosilica on rheological and mechanical properties of fly ash-cement mortar. Cem. Concr Compos. 35,12- 22. (2013).

16. Quercia, G., Hüsken, G. and Brouwers, HJH., Water demand of amorphous nanosilica and its impact on the workability of cement paste.Cem. Concr.Res. 42(2), 344- 57(2012).

17. Abd El Aleem, S., Heikal, M. and Morsi, W.M., Hydration characteristic, thermal expansion and microstructure of cement containing nano-silica. Constr. Build Mater. 59,151- 60 (2014).

18. Byung-Wan, J., Chang-Hyun, K., Ghi-Ho, T. and Jong-Bin P., Characteristics of cement mortar with nano-SiO2 particles. Constr. Build Mater. 21,1351- 5 (2007).

19. Stefanidou, M. and Papayianni I., Influence of nano-SiO2 on the Portland cement pastes. Compos. Part B 43, 2706- 10 (2012).

20. Ji Tao., Preliminary study on the water permeability and microstructure of concrete incorporating nano-SiO2. Cem. Concr.Res. 35,1943- 7 (2005).

21. Li, H., Xiao, H., Yuan, J. and Ou J., Microstructure of cement mortar with nanoparticles. Compos (Part B) Eng. 35,185- 9.( 2004).

22. Qing, Y., Zenan ZH, Deyu K. and Rongshen CH., Influence of nano-SiO2 addition on properties of hardened cement paste as compared with silica fume. Constr. Build Mater. 21,539-45(2007) 
23. Mukharjee, B.B. and Barai, S.V., Assessment of the influence of Nano-Silica on the behavior of mortar using factorial design of experiments.Constr. .Build Mater. 68,416- 25 (2014).

24. Hou, P., Cheng, X., Qian, J., Zhang, R., Cao, W. and Shah SP., Characteristics of surface treatment of nano-SiO2 on the transport properties of hardened cement pastes with different water-to-cement ratios.Cem.Concr. Compos.55, 26- 33 (2015).

25. Tob'n, J.I., Paya, J., Borrachero, M.V. and Restrepo, O.J., Mineralogical evolution of Portland cement blended with silica nanoparticles and its effect on mechanical strength. Constr. Build Mater. 36,736- 42 (2012).

26. Bjornstrom, J., Martinelli, A., Matic, A., Borjesson, L. and Panas I., Accelerating effects of colloidal nanosilica for beneficial calcium-silicate-hydrate formation in cement. Chem. Phys. Lett. 392(1-3):242- 8. (2004).

27. Tob'n J.I., Paya, J. and Restrepo, O.J., Study of durability of Portland cement mortars blended with silica nanoparticles. Constr. Build Mater. 80, 92- 97 (2015).

28. Ghasemi, A.M.R., Parhizkar, T. and Ramezanianpour, A.A., Influence of colloidal nanoSiO2 addition as silica fume replacement material in properties of concrete. In: Proceeding of the second international conference on sustainable construction materials and technologies. Ancona, Italy (2010).

29. Belkowitz, J. and Armentrout, D.L., The investigation of nano-silica in the cement hydration process. ACI Special Publication; [SP267-08:87-100] (2009).

30. Leemann, A. and Winnefeld, F., The effect of viscosity modifying agents on mortar and concrete. Cem. Concr. Compos. 29(5), 341- 9 (2007).

31. Porro, A., Dolado, J.S., Campillo, I., Erkizia, E., de Miguel, Y.R., Saez de Ibarra Y. and Ayuela, A., Effects of nanosilica additions on cement pastes. In: Dhir RK, Newlands MD, Csetenyi LJ, (Ed.). Applications of Nanotechnology in Concrete Design. Thomas Telford, London; p. 87-95. (2005).

32. Shih, J.Y., Chang T.P. and Hsiao, T.C., Effect of nanosilica on characterization of Portland cement composite. Mater. Sci. Eng. 424 (1-2), 266- 74. (2006).

33. Thuadaij, N. and Nuntiya, A., Synthesis and characterization of nanosilica from rice husk ash prepared by precipitation method. J. Nat. Sci. Special Issue on Nanotechnology, 7(1), 59- 65 (2008).

34. Gaitero, J.J., Campillo, I. and Guerrero, A., Reduction of the calcium leaching rate of cement paste by addition of silica nanoparticles. Cem. Concr. Res.38(8-9),1112-8 (2008).

35. Gaitero, J.J., Campillo, I., Mondal, P. and Shah, S.P., Small changes can make a great difference. In: Transp. Res. Rec: J. Transp. Res. Board. Washington DC: Transp Res Board Natl Acad; p. 1- 5(2010). 
36. Givi, A., Rashid, S., Aziz, F., Amran, M. and Salleh M., Experimental investigation of the size effects of $\mathrm{SiO}_{2}$ nano-particles on the mechanical properties of binary blended concrete. Compos. Part B: Eng. 41(8), 673- 7. (2010).

37. Uysal, M. and Yilmaz, K., Effect of mineral admixtures on properties of selfcompacting concrete. Cem. Concr. Compos. 33, 771- 6. (2011).

38. Laibao, L., Yunsheng, Z., Wenhua , Z., Zhiyong, L. and Lihua , Z., Investigating the influence of basalt as mineral admixture on hydration and microstructure formation mechanism of cement. Constr. Build Mater. 48, 434- 40. (2013).

39. Saraya, M.E.S., Study the pozzolanic activity of fresh basalt. Mater. Sci.Eng. 1, 40-50. (2011).

40. Saraya, M.E.S., Study physico-chemical properties of blended cements containing fixed amount of silica fume, blast furnace slag, basalt and limestone, a comparative study.Constr. Build Mater. 72,104-112. (2014)

41. Kelestemur, O. and Demirel, B., Corrosion behavior of reinforcing steel embedded in concrete produced with finely ground pumice and silica fume. Constr. Build Mater .24,1898-905. (2010).

42. Binic, H., Aksogan, O., Sevinc, A.H. and Kucukonder, A., Mechanical and radioactivity shielding performances of mortars made with colemanite, barite, ground basaltic pumice and ground blast furnace slag. Constr. Build Mater. 50, 177-83. (2014).

43. Binici, H., Aksogan, O., Grür, E.B., Kaplan, H. and Bodur, M.N., Performance of ground blast furnace slag and ground basaltic pumice concrete against seawater attack. Constr. Build Mater. 22,1515- 26 (2008).

44. Binici, H., Kapur, S., Arocena, J. and Kaplan H., The sulphate resistance of cements containing red brick dust and ground basaltic pumice with sub-microscopic evidence of intra-pore gypsum and ettringite as strengtheners. Cem. Concr.Compos. 34, 279- 87 ( 2012).

45. Uncik, S. and Kmecova, V., The effect of basalt powder on the properties of cement composites. Procedia Engineering. 65, 51-56 (2013).

46. Binici, H., Effect of crushed ceramic and basaltic pumice as fine aggerates on concreat mortars properties. Constr. Build Mater. 21, 11991- 7 (2007)

47. Binici, H., Temiz, H. and Kose, M.M., The effect of fineness on the properties of the blended cements incorporating ground granulated blast furnace slag and ground basaltic pumice. Constr. Build Mater .21, 1122- 8 (2007).

48. Cory, H., Hatem, M.S., Adel, E., Sami, H.R., Use of basalt fibers for concrete structures Constr. Build Mater. 96, 37- 46. (2015).

49. ASTM Standards. Standard test method for normal consistency of hydraulic cement. ASTM Designation (C187- 83) (1983).

Egypt. J. Chem. 59, No.4 (2016) 
50. El-Didamony, H., Heikal, M. and Abd. El.Aleem S. Influence of delayed addition time of sodium sulfanilate phenol formaldehyde condensate on the hydration characteristics of sulfate resisting cement pastes containing silica fume. Constr Build Mater 37, 269- 76 (2012).

51. ASTM C109. Strength test method for compressive strength of hydraulic cement mortars( 2007).

52. Abd-El-Aziz, M.A., Abd. El. Aleem, S . and Heikal M., Physico-chemical and mechanical characteristics of pozzolanic cement pastes and mortars hydrated at different curing temperatures. Constr. Build Mater. 26, 310- 6 (2012).

53. El-Didamony, H., Abd-El-Aziz, M.A., Abd El-Aleem S. and Heikal M., Hydration and durability of sulfate resisting and slag cement blends in Qaron Lake water. Cem. Concr. Res. 35, 1592- 600. (2005).

54. Ramachandran, V.S. , Application of differential thermal analysis in cement chemistry. New York: Chemical Publishing Company; (1969).

55. EL- Didamony, H., Abdel Rahman, A., Nassar, F. and Sayara, M., Effect of basalt on the burnability of raw meal of Portland cement clinker. Indian Journal of Engineering and Materials Science, 17, 282-8. (2010).

56. Hassaan, M.Y., Basalt rock as an alternative raw material in Portland cement manufacture. Mater. Letter. 50,172-8. (2001).

57. Aiu, M., The Chemistry and Physics of Nano Cement. Loyola Marymount University NSF- REU University of Delaware, (2006).

58. Abd El-Aziz M, Abd El-Aleem S., Heikal, M. and El-Didamony, H., Effect of polycarboxylate on rice husk ash pozzolanic cement. Silicon Ind. 69(9-10), 73- 84 (2004).

59. Neville, A.M., Properties of Concrete. $4^{\text {th }}$ ed. England: ELBS with Addition Wesley Longman(1996). 


\section{تأثير النانو سيليكا علي خواص التأدرت وقوي التحمل لعجائن

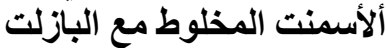

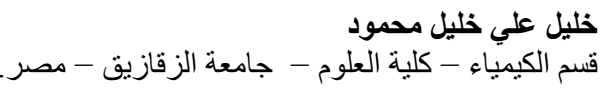

يهدف هذا البحث الي دراسة تأثير النانو سيليكا علي عجائن ألأسمنت المخلوطمع

$$
\text { البازلت هن الت }
$$

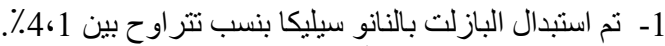

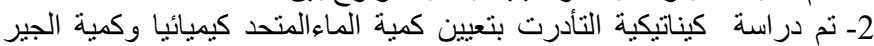

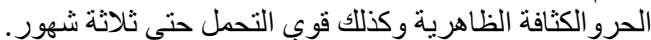

تم تعيين نواتج التأدرت باستخدام ألأشعة ألسينية (XRD) و التحليل $-3$

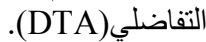

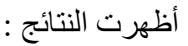

1 - استبدال النانوسيليكا تزيد من الماء المتحد كيميائيا وكذلك قوي التحمل تزيد

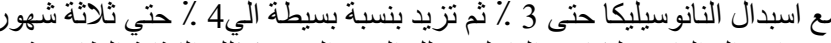

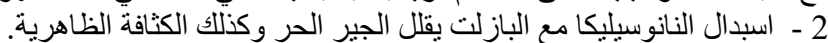

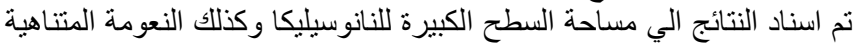

الصغر للنانوسيليكا. 